\title{
BMJ Open Sex and age differences in clinically significant symptoms of depression and anxiety among people in Australia in the first month of COVID-19 restrictions: a national survey
}

Karin Hammarberg (D) , Thach Tran (D), Maggie Kirkman, Jane Fisher (D)

To cite: Hammarberg K, Tran T, Kirkman M, et al. Sex and age differences in clinically significant symptoms of depression and anxiety among people in Australia in the first month of COVID-19 restrictions: a national survey. BMJ Open 2020;10:e042696. doi:10.1136/ bmjopen-2020-042696

- Prepublication history and additional material for this paper is available online. To view these files, please visit the journal online (http://dx.doi.org/10. 1136/bmjopen-2020-042696).

Received 14 July 2020 Revised 13 0ctober 2020 Accepted 08 November 2020

Check for updates

(c) Author(s) (or their employer(s)) 2020. Re-use permitted under CC BY-NC. No commercial re-use. See rights and permissions. Published by BMJ.

Global and Women's Helath, School of Public Health and Preventive Medicine, Monash University, Melbourne, Victoria, Australia

Correspondence to Dr Karin Hammarberg; karin.hammarberg@monash. edu

\section{ABSTRACT}

Objectives To identify sex and age differences in clinically significant symptoms of depression and anxiety and the factors associated with these differences among adults in Australia during COVID-19-related restrictions.

Design Anonymous online survey.

Setting Australia.

Participants Adults aged over 18 years living in Australia were eligible and 13829 contributed complete data. Of these, 13762 identified as female (10 434) or male (3328) and were included in analyses.

Interventions None.

Outcome measures Clinically significant symptoms of depression ( $\geq 10$ on Patient Health Questionnaire 9) or anxiety ( $\geq 10$ on Generalized Anxiety Disorder Scale 7 (GAD-7)), and experiences of irritability (GAD-7 item 6).

Results Women were more likely than men to have clinically significant symptoms of depression (26.3\% (95\% Cl 25.4 to 27.1$)$ vs $20.1 \%$ (95\% Cl 18.7 to 21.5$), p<0.001)$ and anxiety $(21.8 \%(95 \% \mathrm{Cl} 21.0$ to 22.6$)$ vs $14.2 \%$ (95\% Cl 13.0 to 15.4), $\mathrm{p}<0.001$ ) and to have experienced irritability in the previous fortnight $(63.1 \%(95 \% \mathrm{Cl} 62.1$ to 64.0$)$ vs $51.4 \%$ (95\% Cl 49.7 to 53.2$), \mathrm{p}<0.001)$. They were also more likely than men to be doing unpaid work caring for children $(22.8 \%(95 \% \mathrm{Cl} 22.0$ to 23.6$)$ vs $8.6 \%$ (95\% Cl 7.7 to 9.6), $\mathrm{p}<0.001$ ) and dependent relatives (9.8\% (95\% Cl 9.2 to 10.3$)$ vs $5.7 \%$ (95\% Cl 4.9 to 6.5$)$, $\mathrm{p}<0.001)$ which made significant contributions to the mental health outcomes of interest. Loss of employment, fear of contracting COVID-19 and feeling a severe impact of the restrictions were associated with poorer mental health in women and men of all ages.

Conclusions Rates of clinically significant symptoms of depression and anxiety were higher among women than men. Rather than being intrinsically more vulnerable to mental health problems during the COVID-19 pandemic, the higher risk of symptoms of anxiety and depression among women may in part be explained by their disproportionate burden of unpaid caregiving.

\section{INTRODUCTION}

As the WHO declared the SARS-CoV-2 (resulting in COVID-19) outbreak a pandemic, many countries adopted restrictions on
Strengths and limitations of this study

- The first to quantify population prevalence of clinically significant symptoms of depression and anxiety among adults in Australia in month 1 of COVID-19 restrictions.

- Standardised measures of depression and anxiety were used to permit comparisons with equivalent COVID-19 and non-COVID-19-affected populations.

- We ascertained sex and age differences in factors contributing to poorer mental health.

- Almost $75 \%$ of respondents were women.

- As this was a cross-sectional study, causal relationships cannot be established with certainty.

people's movements and activities to limit its spread. In Australia, the first confirmed case of COVID-19 was identified in late January $2020 .{ }^{1}$ The spread of the virus was initially slow but upward trends in infection rates and the seriousness of this threat to public health led to the establishment of the National Cabinet, an intergovernmental decisionmaking forum, to coordinate the national response to the COVID-19 pandemic in Australia. ${ }^{2}$ In late March, national lockdown measures were mandated to limit the spread of the virus. They included requirements to stay at home except for a few specified reasons, work from home wherever possible, limit physical proximity, meet online and not in person, avoid visits to residential aged care facilities, limit attendance at weddings to five and at funerals to 10 people, cancel interstate and international travel and close schools and other educational institutions and move to learning from home.

As a result of the restrictions, economic activity stalled and unemployment soared. Concerns expressed by health professionals about the mental health consequences of 
being confined to home, loss of employment, financial strain, loss of freedom to move and uncertainty about the future have been widely reported in the media. ${ }^{3-5}$ These media reports have focused on the likelihood of the pandemic and its associated restrictions increasing the risk of severe mental illness and rates of suicide. However, the possible implications of the COVID-19 restrictions for psychological well-being at a population level have received less attention.

Studies in Australia, the USA, China and the UK have reported that COVID-19-related restrictions have adversely affected women's mental health more than men's but the potential underlying reasons for this have not been described. ${ }^{6-10}$

Experts call for high-quality population-level data on the mental health effects of the COVID-19 pandemic to inform government responses, to mitigate adverse effects and to prepare for future national crises. ${ }^{11}$ This should include identifying factors that increase the risk of poor mental health in subgroups of the population.

The aim of this component of a larger project was to identify sex and age differences in clinically significant symptoms of depression and anxiety and the factors associated with these among adults in Australia during the first month of COVID-19-related restrictions.

\section{METHOD}

Patient and public involvement

No patient was involved.

\section{Design}

A short, anonymous online survey of people living in Australia aged at least 18 years was launched 4 days after the COVID-19 restrictions were implemented. It included demographic questions; study-specific, fixed-responseoption questions about experiences of COVID-19 and the associated restrictions; and two widely used standardised psychometric instruments measuring symptoms of depression and anxiety.

A sample size of 3074 people is required to estimate the prevalence of people $(20 \%)$ with a mental health problem (at the precision of $2 \%$ taking into account design effect=2). ${ }^{12}$

Detailed information about the design, data source and procedure has been published. ${ }^{13}$

\section{Sociodemographic questions}

Study-specific questions were used to ascertain age, area of residence, gender, and living and work circumstances.

Socio-Economic Indexes for Areas (SEIFA) was derived from each respondent's postcode using the most recent Australian Bureau of Statistics data. ${ }^{14}$ SEIFA provides measures of socioeconomic conditions by geographic area.

Experience of COVID-19 and the associated restrictions Study-specific questions assessed:
1. Direct experience of COVID-19: whether the respondent had been diagnosed with or tested for COVID-19, or lived with or knew someone with COVID-19: yes/no.

2. Whether a job had been lost because of COVID-19 restrictions: yes/no.

3. Worry about contracting COVID-19: a visual analogue scale with scores from 0 (not at all worried) to 10 (extremely worried).

4. How badly COVID-19 restrictions had affected daily life: a visual analogue scale with scores from 0 (not at all badly) to 10 (very badly).

\section{Psychological well-being}

Two standardised psychometric instruments were used to assess symptoms of depression and generalised anxiety experienced over the previous 2 weeks.

\section{Patient Health Questionnaire 9}

The Patient Health Questionnaire 9 (PHQ-9) ${ }^{15}$ is a 9-item scale asking respondents to state how often they have experienced each depressive symptom in the last fortnight on a 4-point scale: $0=$ Not at all, $1=$ Several days, $2=$ More than half the days, $3=$ Nearly every day. Aggregated responses yield a scale indicative of symptom severity. Formally validated against diagnostic psychiatric interviews, a PHQ-9 score $\geq 10$ has sensitivity of $88 \%$ and specificity of $88 \%$ for major depression. PHQ-9 scores of 5-9 represent mild, 10-14 moderate, $15-19$ moderately severe and $\geq 20$ severe depressive symptoms.

\section{Generalized Anxiety Disorder Scale 7}

The Generalized Anxiety Disorder Scale 7 (GAD-7) ${ }^{16}$ is a 7 -item scale assessing common symptoms of anxiety that uses the same response options as PHQ-9. In a formal validation against psychiatric interviews, a GAD-7 score $\geq 10$ has sensitivity of $89 \%$ and specificity of $82 \%$ to detect generalised anxiety disorder. Scores of 5-9 represent mild, 10-14 moderate and 15-21 severe anxiety. Higher scores are strongly associated with functional impairment. GAD-7 item 6 asks whether the respondent is 'Becoming irritable or easily annoyed'.

\section{Procedure}

The survey was built in Qualtrics Insight Platform (Qualtrics, Provo, Utah) (online supplemental material). It was available from 3 April to 2 May 2020. A link to the survey was hosted on the Monash University website (https:// www.monash.edu/medicine/living-with-covid-19-restrictions-survey) and information about it was distributed widely on news and social media platforms including the national broadcaster ABC and Facebook and through organisational and personal networks.

\section{Data management and statistical analysis}

The outcomes were whether, in the last fortnight, the respondent had experienced:

1. Clinically significant symptoms of depression: PHQ-9 scores $\geq 10$. 
2. Clinically significant symptoms of anxiety: GAD-7 scores $\geq 10$.

3. Becoming easily annoyed or irritable: GAD-7 item 6 score $>0$.

The visual analogue scales were categorised into two groups: not at all or none to moderate (0-7) and high $(\geq 8)$.

Data were analysed in two stages.

1. Sociodemographic characteristics, experience of COVID-19 and the associated restrictions, and psychological well-being were described separately by women and men. Tests of statistical significance $\left(\chi^{2}\right)$ were conducted to compare characteristics by sex.
2. Sex and age differences in the factors associated with clinically significant symptoms of depression and anxiety and becoming easily annoyed or irritable were examined using multiple logistic regression analyses for each of the four subgroups (women 18-49 years, women 50 years and older, men 18-49 years and men 50 years and older). Multiple logistic regression analyses were performed for each of the outcomes and included as potential explanatory factors sociodemographic characteristics and experiences of COVID.

Only complete data were included in analyses, which were conducted using STATA V.16 (StataCorp, College Station, Texas).

\begin{tabular}{|c|c|c|c|c|}
\hline & Total n (\%) & Females $\mathrm{n}(\%)$ & Males n (\%) & $P$ value \\
\hline Total & 13762 & $10434(75.8)$ & 3328 (24.2) & \\
\hline Age group & & & & $<0.001$ \\
\hline $18-29$ & $1323(9.6)$ & $1033(9.9)$ & $290(8.7)$ & \\
\hline $30-39$ & $2275(16.5)$ & $1860(17.8)$ & $415(12.5)$ & \\
\hline $40-49$ & $2842(20.7)$ & $2334(22.4)$ & $508(15.3)$ & \\
\hline $50-59$ & $3055(22.2)$ & $2309(22.1)$ & $746(22.4)$ & \\
\hline $60-69$ & $2825(20.5)$ & 2016 (19.3) & $809(24.3)$ & \\
\hline $70+$ & $1442(10.5)$ & $882(8.5)$ & $560(16.8)$ & \\
\hline SEIFA quintiles & & & & $<0.001$ \\
\hline Quintile 1 (lowest socioeconomic position) & $1086(7.9)$ & $760(7.3)$ & $326(9.8)$ & \\
\hline Quintile 2 & $1534(11.2)$ & $1127(10.8)$ & 407 (12.2) & \\
\hline Quintile 3 & $2222(16.2)$ & $1670(16.0)$ & $552(16.6)$ & \\
\hline Quintile 4 & $3024(22.0)$ & $2313(22.2)$ & $711(21.4)$ & \\
\hline Quintile 5 (highest socioeconomic position) & $5896(42.8)$ & $4564(43.7)$ & $1332(40)$ & \\
\hline Living situation & & & & $<0.001$ \\
\hline On your own & $2646(19.2)$ & $2033(19.5)$ & $613(18.4)$ & \\
\hline $\begin{array}{l}\text { With only your partner/your partner and children/ } \\
\text { adult family members }\end{array}$ & $9594(69.7)$ & $7190(68.9)$ & $2404(72.2)$ & \\
\hline With children and without a partner & $576(4.2)$ & $527(5.1)$ & $49(1.5)$ & \\
\hline In a shared house with non-family members/other & $946(6.9)$ & $684(6.6)$ & $262(7.9)$ & \\
\hline Doing unpaid work caring for children & $2664(19.4)$ & $2377(22.8)$ & $287(8.6)$ & $<0.001$ \\
\hline Doing unpaid work caring for dependent relatives & $1205(8.8)$ & $1017(9.8)$ & $188(5.7)$ & $<0.001$ \\
\hline Lost job because of COVID-19 & $1241(9.0)$ & $964(9.2)$ & $277(8.3)$ & 0.108 \\
\hline $\begin{array}{l}\text { Highly worried about contracting COVID-19 (scale } \\
\text { score } \geq 8 \text { ) }\end{array}$ & 2167 (15.8) & $1730(16.6)$ & $437(13.1)$ & $<0.001$ \\
\hline $\begin{array}{l}\text { High adverse impact of restrictions } \\
\text { (scale score } \geq 8 \text { ) }\end{array}$ & $3414(24.8)$ & $2661(25.5)$ & $753(22.6)$ & 0.001 \\
\hline $\begin{array}{l}\text { Clinically significant symptoms of depression, PHQ-9 } \\
\text { score } \geq 10\end{array}$ & $3408(24.8)$ & $2740(26.3)$ & $668(20.1)$ & $<0.001$ \\
\hline $\begin{array}{l}\text { Clinically significant symptoms of anxiety, GAD-7 score } \\
\geq 10\end{array}$ & $2747(20.0)$ & $2275(21.8)$ & $472(14.2)$ & $<0.001$ \\
\hline $\begin{array}{l}\text { Becoming easily annoyed or irritable, } \\
\text { GAD-7 item } 6>0\end{array}$ & $8291(60.2)$ & $6579(63.1)$ & $1712(51.4)$ & $<0.001$ \\
\hline
\end{tabular}

GAD-7, Generalized Anxiety Disorder Scale 7; PHQ-9, Patient Health Questionnaire 9; SEIFA, Socio-Economic Indexes for Areas. 
Table 2 Factors associated with clinically significant symptoms of depression (PHQ-9 scores $\geq 10$ )

\begin{tabular}{|c|c|c|c|c|}
\hline & \multicolumn{2}{|l|}{ Females } & \multicolumn{2}{|l|}{ Males } \\
\hline & $18-49$ years old & $\begin{array}{l}50 \text { years old and } \\
\text { above }\end{array}$ & 18-49 years old & $\begin{array}{l}50 \text { years old and } \\
\text { above }\end{array}$ \\
\hline \multicolumn{5}{|l|}{ SEIFA quintiles } \\
\hline \multicolumn{5}{|l|}{ Quintile 1 (lowest SEP) } \\
\hline Quintile 4 & $0.78(0.6 ; 1.01)$ & $0.78(0.58 ; 1.03)$ & $0.95(0.55 ; 1.64)$ & $0.85(0.54 ; 1.33)$ \\
\hline Quintile 5 (highest SEP) & $0.62(0.48 ; 0.8)$ & $0.71(0.55 ; 0.93)$ & $0.87(0.52 ; 1.45)$ & $0.7(0.46 ; 1.07)$ \\
\hline Doing unpaid work caring for children & $0.83(0.72 ; 0.95)$ & $1.33(1.05 ; 1.67)$ & $1.21(0.82 ; 1.78)$ & $1.15(0.66 ; 2.03)$ \\
\hline $\begin{array}{l}\text { Doing unpaid work caring for dependent } \\
\text { relatives }\end{array}$ & $1.52(1.21 ; 1.91)$ & $1.55(1.26 ; 1.91)$ & $1.8(1.02 ; 3.19)$ & $1.47(0.89 ; 2.44)$ \\
\hline $\begin{array}{l}\text { High adverse impact of restrictions (scale } \\
\text { score } \geq 8 \text { ) }\end{array}$ & $3.34(2.93 ; 3.81)$ & $2.81(2.41 ; 3.28)$ & $2.91(2.2 ; 3.84)$ & $4.36(3.32 ; 5.72)$ \\
\hline
\end{tabular}

Bolded values are statistically significant

PHQ-9, Patient Health Questionnaire 9; SEIFA, Socio-Economic Indexes for Areas; SEP, socioeconomic position.

\section{RESULTS}

Of the 15121 respondents who began the questionnaire, $13829(91.5 \%)$ contributed complete data. Of these, 13762 identified as either female or male and were included in analyses. We excluded people from the analyses reported in this paper who did not identify as either female or male because the size of the group $(n=67)$ was relatively small and, in our opinion, the needs of this group warrant distinct consideration.

\section{Respondent characteristics}

Respondents' characteristics are presented in table 1. Three-quarters of the respondents were women. All age groups and socioeconomic positions were represented. About 1 in 5 respondents were living on their own. Women were more likely than men to have clinically significant symptoms of depression and anxiety and to report irritability. They were also more likely to do unpaid work caring for children and dependent relatives. Almost 1 in 10 had lost their job as a result of COVID-19. About 1 in 7 were highly worried about contracting COVID-19 and 1 in 4 perceived that the restrictions had a highly adverse effect on their lives.

\section{Factors associated with mental health outcomes}

The factors associated with clinically significant symptoms of depression and anxiety and experiencing irritability for women and men in two age groups are shown in tables 2-4, respectively. Being highly worried about contracting COVID-19 and perceiving that the restrictions affected personal life very badly were associated with all outcomes for both women and men of all ages.
Sex and age differences in factors influencing risk of clinically significant symptoms of depression

For women and men in both age groups, living with family rather than living on their own or with non-family members reduced the risk of clinically significant symptoms of depression, and the loss of a job as a result of COVID-19 increased the risk. Occupying a higher socioeconomic position was protective for all groups, but this reached statistical significance only for women. Unpaid work caring for children increased the risk for women aged $>50$ years and decreased the risk for younger women. The effect on men of caring for children was not significant. Caring for dependent relatives increased the risk for all except men aged $>50$ years.

Sex and age differences in factors influencing risk of clinically significant symptoms of anxiety

Living with family was protective for all except for women aged $>50$ years, for whom it increased the risk of clinically significant symptoms of anxiety. Unpaid work caring for children also increased the risk for women aged $>50$ years but not for younger women or men. Caring for dependent relatives increased the risk for all but men aged $<50$ years. The loss of a job increased the risk for women aged $>50$ years.

Sex and age differences in factors influencing risk of irritability Living with family increased the risk of reported irritability in women of all ages but not in men. Caring for children increased the risk of irritability in women of all ages and men aged $<50$ years but not in older men. Caring for dependent relatives increased the risk of irritability in 
Table 3 Factors associated with clinically significant symptoms of anxiety (GAD-7 score $\geq 10$ )

\begin{tabular}{|c|c|c|c|c|}
\hline & \multicolumn{2}{|l|}{ Females } & \multicolumn{2}{|l|}{ Males } \\
\hline & $18-49$ years old & $\begin{array}{l}50 \text { years old and } \\
\text { above }\end{array}$ & 18-49 years old & $\begin{array}{l}50 \text { years old and } \\
\text { above }\end{array}$ \\
\hline \multicolumn{5}{|l|}{ SEIFA quintiles } \\
\hline \multicolumn{5}{|l|}{ Quintile 1 (lowest SEP) } \\
\hline Quintile 2 & $0.82(0.6 ; 1.14)$ & $1.18(0.82 ; 1.69)$ & $0.81(0.39 ; 1.71)$ & $0.9(0.49 ; 1.67)$ \\
\hline Quintile 4 & $0.8(0.61 ; 1.05)$ & $1.1(0.79 ; 1.54)$ & $0.99(0.54 ; 1.82)$ & $1.33(0.78 ; 2.27)$ \\
\hline Quintile 5 (highest SEP) & $0.72(0.56 ; 0.94)$ & $1.01(0.74 ; 1.38)$ & $0.82(0.46 ; 1.46)$ & $0.92(0.55 ; 1.54)$ \\
\hline Doing unpaid work caring for children & $0.99(0.86 ; 1.14)$ & $1.34(1.05 ; 1.73)$ & $1.13(0.73 ; 1.75)$ & $1.07(0.57 ; 2.01)$ \\
\hline $\begin{array}{l}\text { Doing unpaid work caring for dependent } \\
\text { relatives }\end{array}$ & $1.34(1.06 ; 1.69)$ & $1.49(1.19 ; 1.87)$ & $1.5(0.8 ; 2.8)$ & $2.32(1.38 ; 3.9)$ \\
\hline $\begin{array}{l}\text { High adverse impact of restrictions (scale } \\
\text { score } \geq 8 \text { ) }\end{array}$ & $3.03(2.65 ; 3.47)$ & $3.13(2.64 ; 3.7)$ & $3.17(2.34 ; 4.29)$ & $4.52(3.31 ; 6.16)$ \\
\hline
\end{tabular}

GAD-7, Generalized Anxiety Disorder Scale 7; SEIFA, Socio-Economic Indexes for Areas; SEP, socioeconomic position.

women and men aged $>50$ years but not in younger men. The loss of a job increased the risk for all but women aged $<50$ years.

\section{DISCUSSION}

To date, most COVID-19-related research has focused on the physical effects of COVID-19. There is now growing evidence about the far-reaching mental health consequences of COVID-19 and its associated governmentimposed restrictions. Population-based studies and studies of healthcare workers and people with pre-existing mental illness demonstrate the significant impact of COVID-19 on people's mental health and well-being. ${ }^{17-22}$ This population-based study adds to existing evidence by identifying sex and age differences in the mental health consequences of COVID-19 restrictions and associated factors. While the loss of a job, being very fearful of contracting COVID-19 and experiencing the restrictions as highly adverse for daily life increased the risk of clinically significant symptoms of anxiety and depression and

Table 4 Factors associated with irritability (GAD-7 item 6 score $>0$ )

\begin{tabular}{|c|c|c|c|c|}
\hline & \multicolumn{2}{|l|}{ Females } & \multicolumn{2}{|l|}{ Males } \\
\hline & 18-49 years old & $\begin{array}{l}50 \text { years old and } \\
\text { above }\end{array}$ & 18-49 years old & $\begin{array}{l}50 \text { years old and } \\
\text { above }\end{array}$ \\
\hline \multicolumn{5}{|l|}{ SEIFA quintiles } \\
\hline \multicolumn{5}{|l|}{ Quintile 1 (lowest SEP) } \\
\hline Quintile 2 & $0.99(0.7 ; 1.41)$ & $1(0.78 ; 1.28)$ & $0.59(0.32 ; 1.11)$ & $0.91(0.64 ; 1.29)$ \\
\hline Quintile 4 & $0.95(0.71 ; 1.28)$ & $1.08(0.86 ; 1.36)$ & $0.81(0.47 ; 1.39)$ & $1.05(0.76 ; 1.46)$ \\
\hline Quintile 5 (highest SEP) & $0.97(0.73 ; 1.29)$ & $0.99(0.81 ; 1.23)$ & $0.84(0.51 ; 1.4)$ & $1.09(0.81 ; 1.48)$ \\
\hline Doing unpaid work caring for children & $1.84(1.58 ; 2.14)$ & $1.37(1.13 ; 1.67)$ & $1.81(1.21 ; 2.7)$ & $1.05(0.71 ; 1.55)$ \\
\hline $\begin{array}{l}\text { Doing unpaid work caring for dependent } \\
\text { relatives }\end{array}$ & $1.42(1.07 ; 1.89)$ & $1.44(1.21 ; 1.72)$ & $0.99(0.54 ; 1.82)$ & $1.69(1.16 ; 2.47)$ \\
\hline $\begin{array}{l}\text { High adverse impact of restrictions (scale } \\
\text { score } \geq 8 \text { ) }\end{array}$ & $2.33(1.96 ; 2.77)$ & $1.84(1.6 ; 2.1)$ & $2.35(1.72 ; 3.22)$ & $2.74(2.19 ; 3.43)$ \\
\hline
\end{tabular}

GAD-7, Generalized Anxiety Disorder Scale 7; SEIFA, Socio-Economic Indexes for Areas; SEP, socioeconomic position. 
of reported irritability in almost all groups, other factors were more likely to affect the mental health of subgroups.

Strengths of this study include the large sample. Validated measures of symptoms of anxiety and depression were used and the survey included questions about respondents' experiences of COVID-19, level of concern about contracting COVID-19, loss of a job due to COVID-19 and how badly COVID-19 restrictions had affected daily life. However, limitations are also acknowledged. There is clear evidence that women are more likely than men to participate in research, as they did in this study where a much higher proportion of respondents were women than men. ${ }^{23}$ As a result, while we are confident that the findings accurately reflect the impact of the restrictions on women's mental health, it is possible that we can be less confident about our understanding of their impact on the mental health of men. Also, because the proportion of respondents occupying the lowest socioeconomic position (whose experiences are likely to have been more difficult) was low, it is possible that the findings might be underestimates of the mental health impacts of the restrictions on the population. Lastly, the cross-sectional design does not allow causal relationships to be established.

The mental health effects of living with family members rather than alone or with non-family members varied by group. While living with family members was protective against symptoms of depression for all groups, it increased the risk of anxiety in women $>50$. Furthermore, it increased the risk of reported irritability for women of all ages but not for men. A possible explanation for these findings is that, as a consequence of COVID-19 and its associated restrictions on the economy and labour market, many young people lost employment and became unable to pay rent and other living expenses and therefore had to move back to their family home. A recent survey revealed that $26 \%$ of households in Australia have an adult child living at home. Of those households, $21 \%$ have an adult child who has returned home because of COVID-19. ${ }^{24}$ The work of re-establishing expectations of how to live together, negotiating contributions to household tasks and dealing with adult children's feelings of frustration may have been largely carried by women which may have contributed to their higher risk of anxiety and irritability.

The unpaid work of caring for children and dependent relatives is disproportionately carried by women. In 2015, women in Australia did 11.5 hours/week more unpaid labour than men. ${ }^{25}$ This pre-existing gender inequality may have been exacerbated by the COVID-19related restrictions during which women reported being much more likely than men to do unpaid work caring for children and dependent relatives. This study found that caring for dependent relatives contributed significantly to the risk of symptoms of depression and anxiety and reported irritability in all groups. In response to the pandemic, many services accessed by people with dependent relatives such as special schools, allied health and disability services became restricted or unavailable. This may have increased the burden of caring and contributed to the poorer mental health of people caring for dependent relatives. Findings were less consistent on the impact on mental health of caring for children. Whereas this contributed significantly to symptoms of depression and anxiety in women aged $>50$, in younger women it reduced the risk of symptoms of depression and it had no effect on the mental health of men. Younger women are likely to have younger children than older women and they may be easier to manage at home than adolescents and young adults. Furthermore, the restriction-related changes in the caring responsibilities of women with young dependent children may have been less dramatic than for those with adolescents or young adult children. The strain of being largely confined to home and managing the needs and frustrations of adolescents or young adults who have to learn from home rather than together with peers at school or university might explain the increased risk of symptoms of depression and anxiety in women aged $>50$.

The findings of this study make a significant contribution to knowledge about the sex-specific and agespecific factors that contribute to poor mental health during government-imposed restrictions in response to the COVID-19 pandemic. They suggest that some factors increase the risk of poor mental health in women and men of all ages. Others, however, are more likely to affect the mental health of women and indicate that, rather than being intrinsically more vulnerable to mental health problems during the COVID-19 pandemic, their higher risk of poor mental health may in part be explained by their disproportionately large share of the burden of unpaid caring work which increased with the closure of usual services like schools and disability services. These findings can inform public health strategies to help at-risk groups recover once the restrictions are lifted. We agree with Ho et al who argue that COVID-19-related mental health responses need to be coordinated and multisectorial and that 'Only by strengthening the psychological defence can nations continue to fight this long-drawn battle and secure success for the future. ${ }^{26}$ We also endorse a recent policy brief issued by the United Nations, which recommends that public health responses to assist in COVID-19 recovery should include rapid implementation of 'a whole-of-society approach to promote, protect, and care for mental health; ensuring widespread availability of mental health and psychosocial support; and supporting recovery from COVID-19 by building mental health services for the future'. ${ }^{27}$

Contributors KH, TT, MK and JF contributed to the conceptualisation of the research question and interpretation of data. TT analysed the data. $\mathrm{KH}$ led the manuscript writing. TT, MK and JF provided constructive feedback and approved the final version.

Funding This work was supported by an untied philanthropic donation from Professor John McBain and Dr Penny Foster.

Competing interests None declared.

Patient consent for publication Not required.

Ethics approval The research was approved by the Monash University Human Research Ethics Committee (2020-24080-42716). 
Provenance and peer review Not commissioned; externally peer reviewed.

Data availability statement Data are available upon reasonable request. Data are available from the first author upon reasonable request.

Supplemental material This content has been supplied by the author(s). It has not been vetted by BMJ Publishing Group Limited (BMJ) and may not have been peer-reviewed. Any opinions or recommendations discussed are solely those of the author(s) and are not endorsed by BMJ. BMJ disclaims all liability and responsibility arising from any reliance placed on the content. Where the content includes any translated material, BMJ does not warrant the accuracy and reliability of the translations (including but not limited to local regulations, clinical guidelines, terminology, drug names and drug dosages), and is not responsible for any error and/or omissions arising from translation and adaptation or otherwise.

Open access This is an open access article distributed in accordance with the Creative Commons Attribution Non Commercial (CC BY-NC 4.0) license, which permits others to distribute, remix, adapt, build upon this work non-commercially, and license their derivative works on different terms, provided the original work is properly cited, appropriate credit is given, any changes made indicated, and the use is non-commercial. See: http://creativecommons.org/licenses/by-nc/4.0/.

\section{ORCID iDs}

Karin Hammarberg http://orcid.org/0000-0002-5988-5865

Thach Tran http://orcid.org/0000-0002-4686-8601

Jane Fisher http://orcid.org/0000-0002-1959-6807

\section{REFERENCES}

1 Australian Government. First confirmed case of novel coronavirus in Australia. Available: https://www.health.gov.au/ministers/the-hongreg-hunt-mp/media/first-confirmed-case-of-novel-coronavirus-inaustralia

2 Menzies J. Explainer: what is the National cabinet and is it Democratic? Available: https://theconversation.com/explainer-whatis-the-national-cabinet-and-is-it-democratic-135036

3 Mannix L. Sydney Morning Herald, 2020. Available: https://www. smh.com.au/national/what-impact-could-the-lockdown-have-on-ourmental-health-20200409-p54inz.html

4 Noyes J. Sydney morning herald, 2020. Available: https://www.smh. com.au/national/australia-urged-to-plan-for-coronavirus-mentalillness-wave-20200428-p54nwo.html

5 Bartone T, Hickie I, McGorry P. Australian medical association, 2020. Available: https://ama.com.au/media/joint-statement-covid-19impact-likely-lead-increased-rates-suicide-and-mental-illness

6 Adams-Prassl A, Boneva T, Golin M, et al. The impact of the coronavirus Lockdown on mental health: evidence from the US. Working papers 2020-030: human capital and economic opportunity Working group, 2020.

7 Hamel L, Lopes L, Muñana C, et al. KFF coronavirus Poll: March, 2020. Available: https://www.kff.org/coronavirus-covid-19/pollfinding/kff-coronavirus-poll-march-2020/

8 Ipsos MORI. 6 in 10 women finding it harder to stay positive dayto-day due to coronavirus. Available: https://www.ipsos.com/ipsosmori/en-uk/6-10-women-finding-it-harder-stay-positive-day-daydue-coronavirus

9 Australian Bureau of Statistics. 4940.0 - Household Impacts of COVID-19 Survey, 2020. Available: https://www.abs.gov.au/
AUSSTATS/abs@.nsf/allprimarymainfeatures/86FF043DD0C1A1B8 CA25856B0081D6F7?opendocument

10 Liu N, Zhang F, Wei C, et al. Prevalence and predictors of PTSS during COVID-19 outbreak in China hardest-hit areas: gender differences matter. Psychiatry Res 2020;287:112921-21.

11 Holmes EA, O'Connor RC, Perry VH, et al. Multidisciplinary research priorities for the COVID-19 pandemic: a call for action for mental health science. Lancet Psychiatry 2020;7:547-60.

12 Patient Focused Medicines Development. Precision, and sample size reference manual. release 16. College Station, TX: StataCorp LLC, 2019.

13 Fisher JR, Tran TD, Hammarberg K, et al. Mental health of people in Australia in the first month of COVID-19 restrictions: a national survey. Med J Aust 2020;213:458-64 https://www.mja.com.au/ journal/2020/mental-health-people-australia-first-month-covid-19restrictions-national-survey

14 Australian Bureau of Statistics. Socio-Economic indexes for areas (SEIFA). Available: http://www.abs.gov.au/websitedbs/censushome. nsf/home/seifa

15 Kroenke K, Spitzer RL, Williams JB. The PHQ-9: validity of a brief depression severity measure. J Gen Intern Med 2001;16:606-13.

16 Spitzer RL, Kroenke K, Williams JBW, et al. A brief measure for assessing generalized anxiety disorder: the GAD-7. Arch Intern Med 2006;166:1092-7.

17 Chew NWS, Lee GKH, Tan BYQ, et al. A multinational, multicentre study on the psychological outcomes and associated physical symptoms amongst healthcare workers during COVID-19 outbreak. Brain Behav Immun 2020;88:559-65.

18 Hao F, Tan W, Jiang L, et al. Do psychiatric patients experience more psychiatric symptoms during COVID-19 pandemic and lockdown? A case-control study with service and research implications for immunopsychiatry. Brain Behav Immun 2020;87:100-6.

19 Ozamiz-Etxebarria N, Dosil-Santamaria M, Picaza-Gorrochategui M, et al. Stress, anxiety, and depression levels in the initial stage of the COVID-19 outbreak in a population sample in the Northern Spain. Cad Saude Publica 2020;36:e00054020.

20 Ozamiz-Etxebarria N, Idoiaga Mondragon N, Dosil Santamaría M, et al. Psychological symptoms during the two stages of Lockdown in response to the COVID-19 outbreak: an investigation in a sample of citizens in northern Spain. Front Psychol 2020;11:1491-91.

21 Wang C, Pan R, Wan X, et al. Immediate psychological responses and associated factors during the initial stage of the 2019 coronavirus disease (COVID-19) epidemic among the general population in China. Int J Environ Res Public Health 2020;17:1729.

22 Wang C, Pan R, Wan X, et al. A longitudinal study on the mental health of general population during the COVID-19 epidemic in China. Brain Behav Immun 2020;87:40-8.

23 Galea S, Tracy M. Participation rates in epidemiologic studies. Ann Epidemiol 2007;17:643-53.

24 Browne K. "Boomeranging" generation moves home due to COVID-19. Available: https://www.finder.com.au/press-release-may2020-boomeranging-generation-moves-home-due-to-covid-19

25 Empolyment.gov. Australian government department of education skills and employment. Available: https://www.employment.gov.au/ newsroom/how-we-share-unpaid-labour-home-informs-employmentpolicy

26 Ho CS, Chee CY, Ho RC. Mental health strategies to combat the psychological impact of COVID-19 beyond paranoia and panic. Ann Acad Med Singap 2020;49:155-60.

27 United Nations. Policy brief: COVID-19 and the need for action on mental health. Available: https://www.un.org/sites/un2.un.org/files/ un_policy_brief-covid_and_mental_health_final.pdf 